\title{
Clinical Outcomes of Tamoxifen and Clomiphene Citrate in Intrauterine Insemination Cycles
}

\author{
${ }^{1}$ Asifa Majeed, ${ }^{2}$ PS Divyashree, ${ }^{3}$ Kamini A Rao
}

\section{ABSTRACT}

Background: Both selective estrogen receptor modulators, tamoxifen and clomiphene have been used for ovulation induction for patients with anovulatory infertility. The aim of this study is to compare the effectiveness of tamoxifen to clomiphene on clinical outcome in intrauterine insemination (IUI) cycles.

Materials and methods: It is a retrospective clinical study. Two hundred and seven women undergoing IUI cycles from July 2013 to July 2014 at Milann-The Fertility Centre, Bengaluru, India were analyzed. Tamoxifen was administered in the dose of $40 \mathrm{mg}$ starting from day $2 / 3$ of the menstrual cycle for a period of 5 days and clomiphene citrate (CC) was administered in the dose of $100 \mathrm{mg}$ from day $2 / 3$ of menstrual cycle for 5 days. Monitoring of ovulation was done by transvaginal ultrasound from day $5 / 6$ till dominant follicle size was more than $18 \mathrm{~mm}$. Highly purified human chorionic gonadotrophin (hCG) in the dose of 5000 IU was given. Double insemination was done at 24 and 36 hours. Luteal phase support was given in form of dydrogesterone $10 \mathrm{mg}$ twice a day for 14 days. Serum beta-hCG was done after 14 days.

Result: In our study, 76 patients recieved clomiphene citrate $(37 \%)$ and 126 patients received tamoxifen (62.9\%). Both the groups were comparable in terms of age, period of infertility, $\mathrm{FSH}$, LH, antral follicle count and their human menopausal gonadotropin (hMG) requirement (Table 1). Thirteen patients $(23.6 \%)$ in CC group and 42 patients $(76.4 \%)$ in tamoxifen group had positive serum beta hCG result. $p$-value was found to be significant $(p=0.016)$ (Table 2$)$.

Conclusion: Tamoxifen was associated with better endometrial thickness and pregnancy rate when compared to clomiphene citrate in ovarian stimulation in IUI cycles.

Keywords: Anovulation, Clomiphene citrate, Intrauterine insemination cycles, Ovarian stimulation, Tamoxifen.

How to cite this article: Majeed A, Divyashree PS, Rao KA. Clinical Outcomes of Tamoxifen and Clomiphene Citrate in Intrauterine Insemination Cycles. Int $\mathrm{J}$ Infertil Fetal Med 2015;6(3):118-121.

Source of support: Nil

Conflict of interest: None

\footnotetext{
${ }^{1}$ Fellow, ${ }^{2}$ Consultant, ${ }^{3}$ Medical Director

${ }^{1-3}$ Department of Reproductive Medicine, Milann-The Fertility Centre, Bengaluru, Karnataka, India
}

Corresponding Author: Asifa Majeed, Fellow, Department of Reproductive Medicine, Department of Reproductive Medicine Milann-The Fertility Centre, Bengaluru, Karnataka, India Phone: 9019291132, e-mail: asifamaj@gmail.com
Date of received: $27-09-15$

Date of acceptance: $15-12-15$

Date of publication: December 2015

\section{INTRODUCTION}

Ovulation is the central event in the reproduction cycle. Ovulatory disorders account for 20 to $25 \%$ of all cases of infertility. ${ }^{1}$ Successful therapy of anovulation is one of the most dramatic advances in infertility management. Nonsteroidal selective estrogen receptor modulators (SERM), such as clomiphene citrate (CC) and tamoxifen, are commonly used to induce ovulation. Selective estrogen receptor modulators are thought to act primarily by binding with estrogen receptors at the hypothalamus. This competitive inhibition results in a perceived drop in endogenous estrogen levels, eventually leading to increased gonadotropin secretion and subsequent induction of ovulation. Clomiphene citrate has been the first-line method of ovulation induction in couples with anovulatory infertility since its introduction in $1956 .^{2}$ Approximately $80 \%$ of women ovulate while using clomiphene, ${ }^{3}$ however, only $40 \%$ of women will achieve pregnancy. ${ }^{4}$ Some authors have proposed that this discrepancy is due to the antiestrogenic effects of clomiphene on the uterus, cervix and vagina, resulting in a thin endometrial lining ${ }^{5}$ and poor cervical mucus. ${ }^{4}$ Another nonsteroidal SERM, tamoxifen, has also been used to induce ovulation. Although commonly used today as an adjuvant therapy in the treatment of breast cancer, its use as an ovulatory agent was first reported by Williamson and Ellis. ${ }^{6}$ Unlike clomiphene, tamoxifen acts as an agonist on the estrogen receptors of the vaginal mucosa and endometrium. Studies on the effects of tamoxifen on cervical mucus have been contradictory. ${ }^{7,8}$ A randomized controlled trial found that tamoxifen was as effective as clomiphene in inducing ovulation. Despite a trend toward improved pregnancy rates with tamoxifen, the study was underpowered to confirm this finding. ${ }^{9}$

\section{AIM}

The study aimed to assess the effect of tamoxifen and CC on clinical outcome in ovarian stimulation in IUI cycles. 


\section{MATERIALS AND METHODS}

It is a retrospective clinical study. Two hundred and seven women undergoing IUI cycles from July 2013 to July 2014 at Milann-The Fertility Centre, Bengaluru were analyzed. Tamoxifen was administered in the dose of $40 \mathrm{mg}$ starting from day $2 / 3$ of the menstrual cycle for a period of 5 days and CC was administered in the dose of $100 \mathrm{mg}$ from day $2 / 3$ of menstrual cycle for 5 days. Inj. HMG $75 / 150 \mathrm{IU}$ was added according to the follicular response. Monitoring of ovulation was done by transvaginal ultrasound. Monitoring of ovulation was done by transvaginal ultrasound from day $5 / 6$ till dominant follicle size was more than $18 \mathrm{~mm}$. Highly purified hCG in the dose of $5000 \mathrm{IU}$ was given. Double insemination was done at 24 and 36 hours. Ultrasound was done from day 11 onward. The occurrence of ovulation was documented by one or more of the following criteria:

- Development of dominant follicle $\geq 17 \mathrm{~mm}$, followed by disappearance

- Reduction in size of dominant follicle by more than $5 \mathrm{~mm}$

- A change in the shape and appearance of internal echoes within the follicle

- Appearance of free fluid in the pouch of Douglas. Luteal phase support was given in form of dydrogesterone $10 \mathrm{mg}$ twice a day for 14 days. Serum beta-hCG was done after 14 days.

\section{Outcomes}

Primary outcomes

- Clinical pregnancy rate

Secondary outcomes

- Endometrial thickness

- Number of follicles $>15 \mathrm{~mm}$ in size.

Clinical pregnancy defined as women with positive serum beta-hCG and ultrasound evidence of gestational sac.

\section{Inclusion Criteria}

Primary or secondary infertility due to:

- Ovulatory dysfunction

- Mild male infertility

- Unexplained infertility

- Tubal factor

- Age 18 to 35 .

\section{Exclusion Criteria}

- Serious adverse effects under CC or known sensitivity to either tamoxifen or CC.

- Severe male factor infertility-TMC $<1 \mathrm{million} / \mathrm{ml}$

- Severe endometriosis

- Poor ovarian responders (according to Bologna criteria).

\section{STATISTICAL ANALYSIS}

\section{Statistical Methods}

Descriptive and inferential statistical analysis has been carried out in the present study. Test of significance for variables: continuous scale-student t-test (two tailed, independent) and for categorical scale-Chi-square/Fisher exact test. The Statistical software namely SAS 9.2, SPSS 15.0, Stata 10.1, MedCalc 9.0.1, Systat 12.0 and R environment ver.2.11.1 were used for the analysis of the data.

\section{RESULT}

In our study, 76 patients received CC (37\%) and 126 patients received tamoxifen (62.9\%). Both the groups were comparable in terms of age, period of infertility, FSH, LH, antral follicle count and their hMG requirement (Table 1). Thirteen patients $(23.6 \%)$ in CC group and 42 patients $(76.4 \%)$ in tamoxifen group had positive serum beta hCG result $\mathrm{p}$-value was found to be significant $(\mathrm{p}=$ 0.016) (Table 2).

\section{INFERENCES}

Results from the study indicate that the mean number of follicles did not differ significantly in patients receiving clomiphene or tamoxifen with $p$-value being 0.629 (Table 2). Endometrial thickness in patients receiving CC was found to be less than patients receiving tamoxifen $(p=0.01)$ (Fig. 1). Pregnancy rates in patients receiving tamoxifen during IUI cycles is significantly higher than those receiving CC with p-value being 0.016 (Fig. 2).

\section{DISCUSSION}

Clomiphene citrate introduced by Greenblatt et $\mathrm{al}^{2}$ is one of the most commonly used agents in ovulation induction.

Table 1: Comparison between baseline variables in both the groups (CC and TAM)

\begin{tabular}{lclll}
\hline $\begin{array}{l}\text { Clinical } \\
\text { variables }\end{array}$ & Protocol & & $\begin{array}{l}\text { Total } \\
(n=76)\end{array}$ & $\operatorname{TAM}(n=129)$ \\
$(n=205)$ & $p$-value \\
\hline $\begin{array}{l}\text { Age in } \\
\text { years }\end{array}$ & $29.71 \pm 3.51$ & $29.12 \pm 2.76$ & $\begin{array}{l}29.34 \pm \\
3.06\end{array}$ & 0.181 \\
Infertility & $3.05 \pm 1.91$ & $2.94 \pm 1.71$ & $\begin{array}{l}2.98 \pm \\
1.77\end{array}$ & 0.687 \\
(years) & & & $5.92 \pm$ & 0.605 \\
FSH & $5.84 \pm 2.01$ & $5.97 \pm 1.52$ & 1.72 & \\
& & & $5.40 \pm$ & 0.886 \\
LH & $5.36 \pm 2.94$ & $5.43 \pm 3.58$ & 3.35 & \\
& & & $7.10 \pm$ & 0.823 \\
AFC & $7.04 \pm 3.12$ & $7.14 \pm 3.08$ & 3.09 & \\
& & & $432.19 \pm$ & 0.202 \\
hMG & $402.96 \pm$ & $449.42 \pm 249.11$ & \\
& 254.62 & & 251.55 & \\
\hline
\end{tabular}

CC: Clomiphene citrate; TAM: Tamoxifen; FSH: Follicle stimulating hormone; LH: Luteinizing hormone; AFC: Antral follicle count; hMG: Human menopausal gonadotropin 
Table 2: Comparison between clinical outcomes in both the groups

\begin{tabular}{lllll}
\hline Variable & $\begin{array}{l}\text { CC } \\
(n=76)\end{array}$ & $\begin{array}{l}\text { TAM } \\
(n=129)\end{array}$ & $\begin{array}{l}\text { Total } \\
(n=205)\end{array}$ & $p$-value \\
\hline $\begin{array}{l}\text { Mean number } \\
\text { of follicles }\end{array}$ & $1.46 \pm 0.68$ & $1.55 \pm 1.91$ & $1.56 \pm 1.56$ & 0.692 \\
$\begin{array}{l}\text { Endometrial } \\
\text { thickness }(\mathrm{mm})\end{array}$ & $8.69 \pm 1.03$ & $9.15 \pm 1.44$ & $8.98 \pm 1.32$ & $0.014^{*}$ \\
Pregnancy rate & $13(17.1 \%)$ & $42(32.6 \%)$ & $55(26.8 \%)$ & $0.016^{*}$
\end{tabular}

${ }^{*}$ Moderately significant ( $p$-value: $0.01<p \leq 0.05$ ); (CC: Clomiphene citrate; TAM: Tamoxifen)

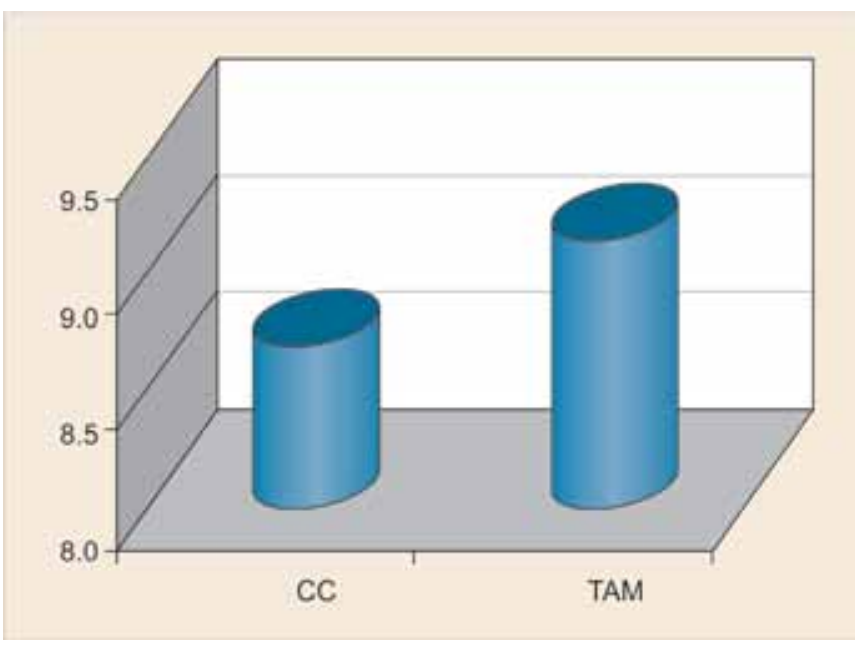

Fig. 1: Endometrial thickness in both the groups (CC and TAM)

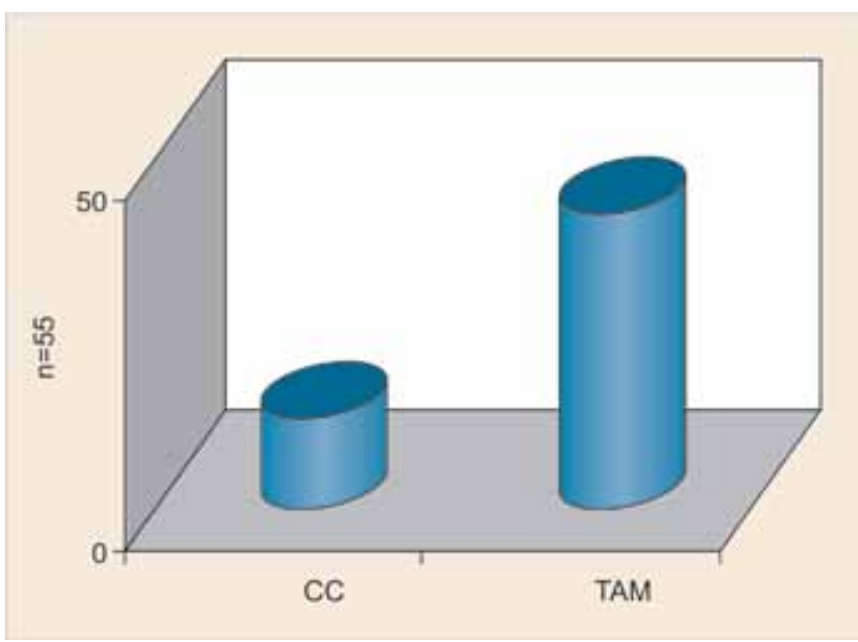

Fig. 2: Pregnancy rate in both the groups (CC and TAM) (CC: Clomiphene citrate, TAM: Tamoxifen)

However, pregnancy rates (30-40\%) with CC are not as good as ovulation rates $(70-80 \%) .{ }^{10}$ Another downside of CC is the controversial suggestion that clomiphene use could be associated with epithelial ovarian cancer. Tamoxifen another antiestrogenic compound very similar structure to CC, in use as an anticancer agent has also been evaluated as a fertility agent. The mechanism of tamoxifen in improving folliculogenesis may involve a direct action on the ovary without intervention of hypothalamo-pituitary system as suggested in the studies by Fukushima et al. ${ }^{11}$ Tamoxifen also has a beneficial effect on the cervical mucus and the endometrium. ${ }^{12}$ Several studies have looked at clomiphene $v$ s tamoxifen as first line therapy in anovulatory infertility.

In our study, 76 patients received CC (37\%) and 126 patients received tamoxifen $(62.9 \%)$. Both the groups were comparable in terms of age, period of infertility, FSH, LH, antral follicle count and their hMG requirement. Thirteen patients $(23.6 \%)$ in CC group and 42 patients (76.4\%) in tamoxifen group had positive serum beta-hCG result $\mathrm{p}$-value was found to be significant $(\mathrm{p}=0.016)$. In a meta-analysis conducted by Steiner AZ et al $2005^{13}$ the use of tamoxifen or $\mathrm{CC}$ resulted in similar ovulation rates [odds ratio (OR) $0.755,95 \%$ confidence interval (CI) $0.513-1.111]$. There was no benefit of tamoxifen over CC in achievement of pregnancy per cycle (OR 1.056, 95\% CI $0.583-1.912$ ) or per ovulatory cycle (OR $1.162,95 \%$ CI 0.632-2.134).The ovulation rates were high in both groups; however, pregnancy rates were much lower. Although the odds of pregnancy were higher after ovulation with tamoxifen, this finding was not statistically significant. Despite the theoretical benefits of tamoxifen, this meta-analysis failed to find a significant benefit of tamoxifen over clomiphene for inducing pregnancy. The similarity in ovulation rates differs from the conclusions by Borenstein et al ${ }^{12}$ who found in a retrospective study of 43 clomiphene-resistant patients that tamoxifen was a superior ovulatory agent. However, Gerhard and Runnebaum ${ }^{14}$ concluded that ovulation rates with tamoxifen did tend to be higher than those with clomiphene in women with oligomenorrhea. Their findings on the relative effects of clomiphene and tamoxifen on pregnancy rates or outcome were inconclusive. Unlike the pooled odds ratio for ovulation induction, there was a fairly imprecise estimate of the odds of pregnancy with tamoxifen $v$ s clomiphene. In our study, the endometrial thickness in CC group was $8.69 \pm 1.03$ and in TAM group it was $9.15 \pm 1.44$ which was found to be significant $(\mathrm{p}=0.014)$. The pregnancy rate in CC group was 17.1 and $32.6 \%$ in TAM group ( $p=0.016$ ). Our findings on the relative effects of clomiphene and tamoxifen on pregnancy rates found higher pregnancy rate in TAM group. In study by Boostanfar et al 2000, ${ }^{9}$ the overall rate of ovulation in the TMX group was 50 of 113 (44.2\%) and in the CC group, 41 of 91 (45.1\%). There were 10 pregnancies in the TMX group and six pregnancies in the CC group. The cycle fecundity per ovulatory cycle was $20.0 \%$ in the TMX group and $14.6 \%$ in the CC group. The overall rate of ovulation and pregnancy were similar with TMX and CC. This study demonstrated that TMX is an effective, but not superior, alternative to $\mathrm{CC}$ for the induction of ovulation in infertile women. However, this study had a small sample size in which 98 anovulatory 
women without other causes of infertility were taken. In our study, Tamoxifen was associated with better endometrial thickness and pregnancy rate than compared to CC. However, a potential limitation of our study is the retrospective design. Secondly, the data taken for the study were taken from a single center, so the sample was small, and the generalizability of the findings may be limited. Thus, more studies are required to assess the clinical outcomes and effectiveness between both the drugs.

\section{CONCLUSION}

Tamoxifen was associated with better endometrial thickness and pregnancy rate than compared to CC in ovarian stimulation in IUI cycles.

\section{REFERENCES}

1. Rowland M. Infertility therapy. Effect of innovations and increasing experience. J Reprod Med 1980 Jul;25(1):41-46.

2. Greenblatt RB, Barfield WE, Jungck CC, Ray AW. Induction of ovulation with MRL/41: Preliminary report. JAMA 1961 Oct 14;178:101-104.

3. Gorlitsky GA, Kase NG, Speroff L. Ovulation and pregnancy rates with clomiphene citrate. Obstet Gynecol 1978 Mar;51(3):265-269.

4. Gysler M, March CM, Mishell DR Jr, Bailey EJ. A decade's experience with an individualized clomiphene treatment regimen including its effect on the postcoital test. Fertil Steril 1982 Feb;37(2):161-167.
5. Eden JA, Place J, Carter GD, Jones J, Alaghband-Zadeh J, Pawson ME. The effect of clomiphene citrate on follicular phase increase in endometrial thickness and uterine volume. Fertil Steril 1989 Feb;73(2):187-190.

6. Williamson JG, Ellis JD. The induction of ovulation by tamoxifen. J Obstet Gynaecol Br Cmnwlth 1973 Sep; 80(9): 844-847.

7. Acharya U, Irvine DS, Hamilton MPR, Templeton AA. The effect of three anti-oestrogen drugs on cervical mucus quality and in-vitro sperm-cervical mucus interaction in ovulatory women. Hum Reprod 1993 Mar;8(3):437-441.

8. Annapurna V, Dhaliwal LK, Gopalan S. Effect of two antiestrogens, clomiphene citrate and tamoxifen, on cervical mucus and sperm-cervical mucus interaction. Int J Fertil Women's Med 1997 May-Jun;42(3):215-218.

9. Boostanfar R. A prospective randomized trial comparing clomiphene citrate with tamoxifen citrate for ovulation induction. Fertil Steril 2001 May;75(5):1024-1026.

10. $\mathrm{Wu} \mathrm{CH}$. A practical approach to clomiphene therapy. Clin Obstet Gynecol 1984 Dec;27(4):953-965.

11. Fukushima T, Maeyama M. Action of tamoxifen on folliculogenesis in the menstrual cycle of infertile patients. Fertil Steril 1983 Aug;40(2):210-214.

12. Borenstein R, Shoham Z, Yemini M, Barash A, Fienstein M, Rozenman D. Tamoxifen treatment in women with failure of clomiphene citrate therapy. Austr NZ J Obstet Gynaecol 1989 May;29(2):173-175.

13. Steiner AZ, Terplan M, Paulson RJ. Comparison of tamoxifen and clomiphene citrate for ovulation induction: a metaanalysis. Hum Reprod 2005 June;20(6):1511-1515.

14. Gerhard, Runnebaum B. Comparison between tamoxifen and clomiphene therapy in women with anovulation. Arch Gynecol 1979;227(4):279-288. 